\title{
EFEITO DE ÚM PROGRAMA DE HIGIENE ORAL SOBRE GENGIVITE EM ESCOLARES
}

\author{
Marisa Maltz* \\ José Oscar Schneider Santos ** \\ Edgar Mario Wagner **
}

MLTZ, Marisa et alii. Efeito de um programa de higiene oral sobre gengivite em escolares. Revista da Faculdade de Odontologia, Porto Alegre, 21-2223-24: 103-19, 1979/82.

Descritores: HIGIENE BUCAL GENGIVITE, PROFILAXIA EM ESCOLARES

axymo

O presente trabalho analisou o cicito de um programa preventivo de higiene oral sobre gengivite em escotares.

Participaram um total de 182 crianças de 8 - 10 anos de idade, alunos do 1 ? grau de um grupo escobr estadual de Porto Alegre.

As crianças foram divididas em um grupo-controle (91 crianças) e um grupo-teste (91 crianças). No exame inicial foi determinado o Indice Gengival.

O programa profilático desenvolvido para o grupo-teste constou dos seguintes procedimentos: sessões supervisionadas semanalmente de escovação (com auxílio do revelador de placa) e uso de fio dental para uso em casa.
Os resultados após nove meses de experiência demonstraram que houve uma diminuição significativa do IG das crianças do grupo-teste nas regiões dos molares e áreas interproximais.

\section{1 - INTRODUÇÃO}

O conhecimento científico atual permite compreender a necessidade de remocão da placa dental como importante medida preventiva da doença periodontal. Sabe-se, igualmente, que quanto mais cedo iniciase um programa de prevenção, melhores serão os resultados, para o indivíduo. A aplicação em escolares possibilita uma relativamente fácil supervisão. $O$ presente trabalho é uma contribuição à tentativa de estabelecer um programa preventivo baseado

\footnotetext{
*Prof. Adjunto do Departamento de Odontologia Preventiva e Social, UFRGS

* "Prof. Adjunto do Departamento de Odontologia Preventive e Social, UFRGS

* * "Prof. Adjunto do Depertamento de Estatística da UFRGS
} 
na remoção dos agentes etiológicos através da higiene oral.

\section{2 - REVISÃO BIBLIOGRÁFICA}

Estudos epidemiológicos $14,43,60$ e investigações em animais e em huma nos $^{1}, 29,36,58$ têm demonstrado uma relação significativa entre a pla. ca dental e a doença periodontal do tipo inflamatório.

A clássica experiência de Lờe et alii35 provou que a supressão de higiene oral resultou em um aumento expressivo da placa dental, com a ocorrência, entre 10 a 21 dias, de gengivite. Esta gengivite desapareceu após alguns dias com a retomada, pelos pacientes, de adequadas medidas de higiene oral.

Ainda que o mecanismo intimo de formação de placa dental e a atividade específica de seus diferentes microrganismos não sejam completamente conhecidos, o peso da evidência dos trabalhos até aqui relacionados indica que: "(1) a placa bacteriana é a única causa direta da gengivite e da doença periodontal marginal. . .'37,70

A sua prevenção deve, em conseqüência, basear-se ou na eliminação da placa dental ou no seu controle, de maneira a mantê-la a um nível não patogênico $18,29,32,33,42$.

O controle da placa dental deve ser ativo, uma vez que foi comprovado não existir uma limpeza natural dos dentes pela mastigação. A mastigação não tem efeito na remoção da placa interdental e da localizada na área cervical dos dentes e da gengiva marginal $1,8,27,32,37,41$.

Pesquisas para prevenir a formação ou modificação da placa seguem três linhas básicas: (1) alteração da tensão superficial dos dentes para interferir com a adesão da placa, (2) agentes antibacterianos (antissépticos e antibióticos) com capacidade de inibir a colonização bacteriana e (3) enzimas coma finalidade de dissolver a matriz inter-bacteriana da placa.

Tentativas de evitar a placa dental por agentes redutores da tensão superficial não têm apresentado resultados satisfatórios 37,42.

Os antibióticos, testados experimentalmente em humanos e em animais $10,17,25,48,53$, apresentaram alguns resultados efetivos como redutores de placa dental, mas o risco de hipersensibilização e/ou indução de resistência microbiana contra-indicam, até o momento, o seu uso por períodos prolongados. Um agente, antimicrobiano que tem sido objeto de intensa investigação $28,38,39,40$ é o gluconato de chlorhexidine, que, usado em bochechos ou aplicações tópicas, apresenta ótimos resultados experimentais na efetiva inibição de formação de placa dental. Por haver uma diminuição acentuada da flora oral pelo uso deste agente, ocasionando miudaniças ecológicas, há necessidade de um maior conhecimento sobre quais as conseqüências que estas podem acarretar.

Tentativas de interferir na síntese da matriz gelatinosa da placa dental (dextranos ou "glucanos") por meio de enzimas sintetizadas por vários fungos apresentaram resultados efetivos em animais experimentais 11,15 , mas o uso de dextranase, em bochechos, para remover placa dental em humanos não tem sido encoraja. dor. 47

Até o momento, todos estes recursos não têm apresentado um resultado efetivo na prevenção da placa den- 
tal, ainda que alguns sejam promissores. Por este motivo, a limpeza mecânica é considerada a medida mais eficaz no controle da placa, quando realizada por indivíduos altamente motivados e apropriadamente instrui$\operatorname{dos}^{12,23,37,44}$.

O papel da higiene oral na doença periodontal inflamatória está bem definido. Estudos clínicos e epidemio$\operatorname{logicos} 2,4,5,9,29,31,51,54,55,56,59$, 60 , têm comprovado que a limpeza mecânica pode prevenir a doença periodontal inflamatória. Lang et alii24, demonstraram, experimentalmente, que a remoção diária da placa dental, ou no mínimo a cada dois dias, é suficiente para controlar a inflamação gengival.

Uma série de experiências clínicas que analisam o papel de diferentes medidas preventivas, de cárie dental e doença periodontal inflamatória, estão sendo desenvolvidas nos paises escandinavos, principalmente desde a década de 60.

Koch e Lindhe19,20,21 analisaram, entre várias medidas preventivas, o efeito de escovação dental diária supervisionada com dentifrícios sem fluor sobre o estado da gengiva $e$ atividade de cárie durante três anos. Foi encontrada uma diferenca estatisticamente significativa na quantidade de placa e gengivite entre o grupo-teste e o grupo-controle. Apesar do grupo-teste apresentar uma redução na incidência de cárie, esta era pequena quando comparada com o efeito de outras medidas preventivas estudadas na investigação, como a escovação diária supervisionada com dentifrícios com fluor e bochechos com soluções de fluor a $0,5 \%$ de duas em duas semanas.

O efeito de profilaxia quinzenal realizada por profissional foi analisa- do por Axelsson e Lindhe $2,4,5,29,31$ durante 3 anos. $O$ programa profilático consistia de: (1) limpeza mecânica de dentes com pasta abrasiva contendo fluor e (2) instruções de higiene oral com ensino de escovação dental (técnica de Bass) e uso de fio dental. A inflamação gengival desapareceu completamente e raras lesões de cárie foram observadas no grupoteste ao final do experimento.

Podemos depreender dos trabalhos comentados que relacionam higiene oral, em termos de escovaça dental, com doenca periodontal inflamatória que o papel da higiene oral na doenca periodontal inflamatória é claro, existindo uma correlação de causa e efeito.

\section{3- HIPOTESES}

\section{HO - IHIPOTESE DE NULIDA- DE)}

O estado da gengiva (baseado nas características clínicas dos diferentes graus de inflamação gengival) dos escolares submetidos a um programa de higiene oral não difere estatisticamente do estado da gengiva dos es. colares que não participaram do mesmo programa, a um nível de 0,05.

$H_{1}$ - (HIPOTESE DE ALTER. NATIVA)

O estado da gengiva (baseado nas características clínicas dos diferentes graus de inflamação gengival) dos escolares submetidos a um programa de higiene oral difere estatisticamente do estado da gengiva dos escolares que não participaram do mesmo programa, a um nível de 0,05 .

\section{4 - MATERIAL E MÉTODO}

Foram examinadas 182 crianças 
de 8 a 10 anos de idade, estudantes do Grupo Escolar Duque de Caxias, bairro Menino Deus, em Porto Alegre, que cursavam os 20,39 e 4 \% anos do 19 grau.

A escolha das crianças nesta faixa etária foi feita pelas seguintes razões:

a) importância da formação do hábito de higiene oral o mais cedo possível;

b) utilização de criánças com desenvolvimento psicomotor suficiente para aprender o uso de fio dental em curto prazo de tempo, uma vez que o experimento teria a duração de 9 meses. Constatou-se que criancas com 8, 9 e 10 anos eram capazes de utilizar o fio dental após 10, 7 e 6 dias de aprendizado, respectivamente 57 .

Os grupos teste e controle pertenciam a turnos diferentes com a finalidade de evitar-se o contato entre as crianças para não haver troca de in. formações e, conseqüentemente, influência no comportamento dos participantes do grupo controle.

Backer Dirks et alii6 indicaram c método aleatório como o mais apro- priado para a seleção dos participantes dos grupos teste e controle. A escolha das crianças do turno da manhã para 0 grupo-teste $e$ as da tarde para o grupo-çontrole foi feita por sorteio antes de qualquer contato com os estudantes.

0 número de crianças no início do experimento foi de 91 em cada grupo, número este superior ao minimo preconizado por Jackson ${ }^{16} \mathrm{e}$ Marthaler 45.

Nos grupos escolares de Porto Alegre, localizados em áreas de nível sócioeconômico baixo, a evasão escolar é grande devido a mobilidade da população, por esta razão escolheuse uma escola localizada em uma área de nível sócioeconômico médio, onde a evasão não é tão acentuada.

Durante os 14 meses de experimento, 3 crianças foram perdidas ( 1 do grupo teste $e$ do controle) devido a troca de escola; a tabela 1 nos dá a distribuição das crianças nos gru. pos teste e controle nos 19 e 29 exames.

TABELA 1 - Número de crianças nos dois grupos: 1 9 exame (março); $2 \%$ exame (dezembro).

\begin{tabular}{lcc}
\hline GRUPOS & 19 EXAME & 2\% EXAME \\
\hline TESTE & 91 & 90 \\
CONTROLE & 91 & 89 \\
\hline
\end{tabular}

\section{1 - Exame Gengival}

As condições gengivais das criancas foram determinadas de acordo com os critérios do índice gengival proposto por Loe \& Silness (1963) ${ }^{34}$, baseados nas característi- cas clínicas dos diferentes graus de inflamação gengival.

Os critérios para o índice gengi. val foram os seguintes: 
0 - ausência de inflamação;

1 - pequena inflamação - leve modificação na cor e pequena modificação na textura;

2 - inflamação moderada - superfície moderadamente brilhante, avermelhada, edemaciada e hipertrófica. Sangramento sob pressão;

3 - inflamação severa - vermelhidão e hipertrofia marcante, tendência ao sangramento espontâneo. Ulceração.

Examinou-se a gengiva de todos os dentes permanentes completamente erupcionados, ou seja, em oclusão. Para cada unidade gengival (bucal, mesial, distal e lingual) foi dado um valor de $0-3$, denominado IG da área. Os escores das quatro áreas de cada dente foram somados e divididos por quatro, obtendo-se - IG do dente. Somando o IG de todos os dentes e dividindo pelo $n$ ? de dentes estabeleceu-se o IG do indivíduo. "O indice é portanto, um escore médio das áreas examinadas" 34 .

Antes do exame, para a obtenção do I.G., as gengivas das crianças foram secas com algodão.

As condições gengivais préexperimentais das crianças estão na tabela 2.

TABELA 2 - Indice gengival das crianças (média, erro padrão) das regiōes dos incisivos e molares, e das áreas interproximais, vestibulares e palatinas, no 1 ? exame. Criancas que participaram dos dois exames gengivais.

\begin{tabular}{lcccc}
\hline \multirow{2}{*}{ GRUPO } & \multicolumn{2}{c}{ Teste $(n=90)$} & \multicolumn{2}{c}{ Controle $(n-89)$} \\
& média & e.p. & média & e.p. \\
\hline Incisivos & 0,945 & 0,038 & 1,189 & $0,037^{*}$ \\
Molares & 0,927 & 0,037 & 1,127 & $0,037^{*}$ \\
Áreas Interproximais & 1,052 & 0,038 & 1,224 & $0,032^{*}$ \\
Áreas Vestibulares + & 0,756 & 0,033 & 0,970 & $0,033^{*}$ \\
$\quad$ Palatinas & & & & \\
\hline TOTAL & 0,946 & 0,034 & 1,152 & $0,031^{*}$ \\
\hline
\end{tabular}

'diferença significativa

Como os IG iniciais do grupo-teste e do grupo-controle diferiam significativamente, toda a análise dos resultados foi realizada em termos de:

(1) comparação entre os índices gengivais iniciais com os finais dentro do mesmo grupo;

(2) comparação das variações do IG dos grupos teste e controle.

Os exames clínicos da gengiva foram anotados em fichas especiais. Os achados eram ditados pelo examina- dor a um auxiliar que anotava na ficha.

\section{2 - Programa de Higiene Oral}

As crianças do grupo-teste foram submetidas a um programa de higiene oral que consistia de:

(1) sessões semanais, supervisionadas, de higiene oral, com as seguintes atividades: 
- revelação de placa (eritrosina: a $0,25 \%$ )

- escovaçao dental ***

- uso de fio dental

(2) instruções de higiene oral e dieta

(3) distribuição de escovas e fio dental para uso em casa.

As crianças do grupo-controle não desenvolveram qualquer atividade.

Instruções de higiene' oral.

As crianças receberam aula teórica sobre saúde oral em grupos de $\mathbf{2 5}$ de cada Vez.

Após, em grupos de cinco, as crianças foram instruidas sobre a maneira correta de escovacão e uso de fio dental através de demonstração com auxílio de modelos. Não se tentou modificar a maneira das crianças escovarem os dentes a não ser que: (1) elas realizassem movimentos lesivos aos dentes e gengivas; (2) nẽo removessem a placa dental satisfatoriamente; quando então, se motivou a criança a desenvolver uma técnica individualizada eficiente.

Bergenholt $z^{8}$, em uma revisão bibliográfica sobre higiene oral não encontrou diferença, estatisticamente significativa, entre os vários métodos de escovação dental quanto à sua capacidade de remoção de placa.

A sistemática de escovação estabelecida foi:

a - vestibular da hemi-arcada inferior direita - de molar a incisivo;

b - vestibular da hemi-arcada inferior esquerda - de incisivo a mo. lar;

\footnotetext{
"Merch - Quimitra Comércio e Indústria S/A.

* "Escove Pró 415 - Laboratórios Warner Ltda.

* * *Johnson \& Johnson Indústria e Comércio.
}

c - vestibular da hemi-arcada superior esquerda - de molar a incisivo;

d - vestibular da hemi-arcada superior direita - de incisivo a molar;

e - lingual da hemi-arcada inferior direita - de molar a incisivo;

$f$ - lingual da hemi-arcada inferior esquerda - de incisivo a molar;

g-palatino da hemi-arcada superior esquerda - de molar a incisivo;

h - palatino da hemi-arcada superior direita - de incisivo a molar;

i - superfícies oclusais inferiores;

j - superfícies oclusais superiores.

A escova dental utilizada no experimento foi a Pró 415 que possui cerdas de nylon. As escovas eram substituidas assim que apresentavam modificações devido ao uso, eram guardadas em caixas identificadas e deixadas na escola.

As primeiras sessões de higiene oral duraram aproximadamente 15 minutos; com o decorrer do tempo as crianças desenvolveram habilidade na realização de escovação e uso de fio dental havendo, como conseqüência, uma diminuição do tempo destas sessões para 10 minutos.

Para não perturbar a aula as atividades experimentais foram realizadas no mesmo dia e hora toda a semana. Como as turmas nas escolas estaduais de Porto Alegre têm, aproximadamente, 30 alunos e as crianças saiam das classes em grupos de 5 durante 10 minutos, havia movimentação na turma durante 1 hora, semanalmente. 
As sessões de higiene oral foram desenvolvidas em uma sala com pias e espelhos.

As sessões de higiene oral compreenderam:

- revelação da placa

- escovação dental

- uso do fio dental
Durante o transcorrer da investigação a ordem dos procedimentos de higiene oral variaram. No quadro 1 estão as várias seqüências utilizadas.

QUADRO 1 - Diferentes seqüências dos procedimentos de higiene oral utilizadas no experimento durante $o$ ano letivo.

\begin{tabular}{|c|c|c|}
\hline $\begin{array}{l}\text { 1ạ SEQUENNCIA } \\
\text { (mês de abril) }\end{array}$ & $\begin{array}{l}\text { 2a SEQUENCIA } \\
\text { (mês de maio a nov.) }\end{array}$ & $\begin{array}{l}\text { 3a SEQUENCIA } \\
\text { (eventualmente) }\end{array}$ \\
\hline $\begin{array}{l}1 \text { 19 revelação da placa } \\
\text { dental }\end{array}$ & 19 uso do fio dental & 10 escovação dental \\
\hline 29 uso do fio dental & 2 ? escovação dental & $\begin{array}{l}20 \text { revelação da placa } \\
\text { dental }\end{array}$ \\
\hline \multirow[t]{2}{*}{39 escovação dental } & $\begin{array}{l}3 \text { ? revelação da placa } \\
\text { dental }\end{array}$ & 39 uso do fio dental \\
\hline & 4 ! reescovação dental & \\
\hline
\end{tabular}

Durante o mês de abril ( 1 ạ seqüência), a revelação da placa dental serviu como orientação da escovação dental.

A partir de maio até o fim de novembro (2: seqüência), a revelação serviu para checar os procedimentos de higiene oral.

Eventualmente, durante 0 transcorrer do experimento, foi adotada a 3 ?̣ seqüência de procedimentos para enfatizar a importância do fio dental; como este ficava avermelhado, demonstrava-se às crianças que a escovação não removia a placa dental in. terproximal.

As crianças do grupo-teste receberam escovas e fio dental para uso em casa.

\section{3 - Anślise Estatistica}

Para a análise estatística do presente trabalho foram utilizadas técnicas não paramétricas.

0 teste Mann-Whitney (Siegel, 1956), foi usado para testar as significâncias das diferenças entre dois grupos independentes (IG dos grupos teste e controle nos diferentes exames). Foi realizada correção de empates. 0 teste Wilcoxon (Siegel, 1956) foi utilizado para testar as significâncias entre duas amostras dependentes (variação do IG dentro de cada um dos grupos do primeiro para o segundo exame). 


\section{5 - RESULTADOS}

\section{1 - Condições Gengivais}

As condições gengivais das criancas ao final da investigação estão nas Tabelas 3, 4, 5, 6 e 7 .

Após 9 meses de experiência, observou-se uma melhora significativa no estado das gengivas, tanto do grupo-teste como do grupo-controle (tabela 3). O grupo-teste, que no início do trabalho apresentava um IG $=0,946$ ficou com um IG $=0,730$, tendo havido uma melhora nas condiçőes gengivais a um nível de signifi. cância de 0,00003 ( $Z=5,311)$. 0 grupo-controle teve seu IG reduzido de 1,152 para $1,044(Z=2,995, P$ $<0,003)$. Nota-se, entretanto, que, apesar de ter havido uma modificacão nos escores dos dois grupos, a redução do IG do grupo-teste foi mais significativa do que a do grupo-controle. Os maiores níveis de significância observados nos dois grupos foram nas faces proximais: grupoteste $-P<0,00003, Z=6,333$, grupo-controle $-P<0,001, Z=$ 3,291; e nos molares: grupo-teste $P<0,00003, Z=5,727$, grupo-con trole $-\mathrm{P}<0,002, \mathrm{Z}=3,140$.

TABELA 3 - Indice gengival médio das regiōes dos incisivos e molares, áreas interproximais, vestibulares e palatinas, após 9 meses de experiência.

\begin{tabular}{lllll}
\hline \multicolumn{1}{c}{ GRUPO } & \multicolumn{2}{c}{$\begin{array}{c}\text { TESTE } \\
\text { (nO=90) }\end{array}$} & \multicolumn{2}{c}{$\begin{array}{c}\text { CONTROLE } \\
\text { (nO=89) }\end{array}$} \\
& média & e.p. & média & e.p. \\
\hline Incisivos & 0,818 & 0,036 & 1,089 & 0,046 \\
Molares & 0,634 & 0,028 & 1,001 & 0,038 \\
Areas interproximais & 0,729 & 0,034 & 1,085 & 0,040 \\
Areas vestibulares + & 0,665 & 0,027 & 0,881 & 0,031 \\
\multicolumn{1}{c}{ Palatinas } & & & & \\
\hline TOTAL & 0,730 & 0,037 & 1,044 & 0,037 \\
\hline
\end{tabular}

Significância das diferenças entre o 1 o e o 2 ? exames do estado da gengiva do grupo-teste, valores de $\mathbf{Z}$ com correção de empates.

\begin{tabular}{lcc}
\hline GRUPO TESTE & Z & \multicolumn{1}{c}{$P$} \\
\hline Incisivos & 3,268 & $<0,001$ \\
Molares & 5,727 & $<0,00003$ \\
Áreas Interproximais & 6,333 & $<0,00003$ \\
Áreas Vestibulares t & 2,713 & $<0,007$ \\
\multicolumn{1}{c}{ Palatinas } & & \\
\hline TOTAL & 5,311 & $<0,00003$ \\
\hline
\end{tabular}

Significância das diferenças entre o 1 e e 02 exames do estado da gengiva do grupo-controle, valores de $Z$ com correç̃o de empates.

\begin{tabular}{lcc}
\hline GRUPO-CONTROLE & $Z$ & $p$ \\
\hline Incisivos & 2,222 & $<0,026$ \\
Molares & 3,140 & $<0,002$ \\
Áreas Interproximais & 3,291 & $<0,001$ \\
Áreas Vestibulares t & 2,387 & $<0,017$ \\
$\quad$ Palatinas & & \\
\hline TOTAL & 2,995 & $<0,003$ \\
\hline
\end{tabular}


A redução percentual do IG, ob. servada nos grupos teste e controle no 2 ? exame, estão nas tabelas 4 e 5 respectivamente.

TABELA 4 - Redução percentual do IG observada no grupo-teste no 2 ? exame (ápós 9 meses de experiência).

\begin{tabular}{lc}
\hline GRUPO-TESTE & REDUÇÃO \% \\
\hline Incisivos & 13,439 \\
Molares & 31,607 \\
Áreas Interproximais & 30,703 \\
Áreas Vestibulares + & 12,037 \\
Palatinas & \\
\hline TOTAL & 22,833 \\
\hline TABELA 5 - Redução percentual do IG observada no grupo-controle no 2\% \\
$\quad$ exame lapós 9 meses de experiência). \\
\hline GRUPO-CONTROLE & \\
\hline Incisivos & $\mathbf{8 , 4 1 0}$ \\
Molares & 11,180 \\
Áreas Interproximais & 11,356 \\
Áreas Vestibulares + & 9,175 \\
Palatinas & \\
\hline TOTAL & 9,375 \\
\hline
\end{tabular}

Quando comparou-se a diferença entre o estado inicial e final das gengivas das crianças do grupo-teste com as do grupo-controle, verificou-se haver uma melhora significativa nas condições gengivaịs das regiões dos molares e das áreas interproximais do grupo-teste. Em relação à região dos incisivos e as áreas vestibulares e palatinas, a diferença entre as melhoras não foi significativa (tabela 6).

A distribuição da freqüência dos valores 0,1 e $2(+3)$ do IG no 1 ? exame e após 9 meses de experiência (2․ exame) estão na tabela 7. A fre- qüência dos escores $2(+3)$ diminuiu do 19 para o 20 exame nos dois grupos participantes do experimento. Entretanto, o grupo-teste apresentou uma diminuicão de $10,5 \%$, enquanto o grupo-controle de 2,5\%. Constatouse que somente $8,9 \%$ das unidades gengivais do grupo-teste possuiam sinais de inflamaço moderada, gengiva edemaciada e com sangramento sob pressão, e no grupo-controle $25,5 \%$ das unidades gengivais apresentayamse sob estas mesmas condições. 
TABELA 6 - Médias das diferenças do IG entre o 19 e o 2 ? exames dos grupos testes e controle.

\begin{tabular}{|c|c|c|c|c|c|}
\hline \multicolumn{6}{|c|}{ MELHORAS NAS CONDIÇŐES GENGIVAIS } \\
\hline \multirow{2}{*}{ G R UPO } & \multicolumn{2}{|c|}{$\begin{array}{c}\text { TESTE } \\
\left(n \varphi^{\prime}=90\right)\end{array}$} & \multicolumn{2}{|c|}{$\begin{array}{c}\text { CONTROLE } \\
(n !=90)\end{array}$} & \multirow{2}{*}{$\begin{array}{c}\text { REDUÇÃO } \\
\%\end{array}$} \\
\hline & médias & e.p. & médias & e.p. & \\
\hline $\begin{array}{l}\text { Incisivos } \\
\text { Molares } \\
\text { Áreas Interproximais } \\
\text { Áreas Vestibulares + } \\
\quad \text { Palatinas } \\
\end{array}$ & $\begin{array}{l}0,127 \\
0,293 \\
0,323 \\
0,091\end{array}$ & $\begin{array}{l}0,038 \\
0,042 \\
0,038 \\
0,033\end{array}$ & $\begin{array}{l}0,100 \\
0,126 \\
0,139 \\
0,089\end{array}$ & $\begin{array}{l}0,043 \\
0,037 \\
0,040 \\
0,031\end{array}$ & $\begin{array}{r}21,3 \\
57,0 \\
57,0 \\
2,2\end{array}$ \\
\hline TOTAL & 0,216 & 0,040 & 0,108 & 0,034 & 50 \\
\hline
\end{tabular}

Significância das diferenças entre as modificações do IG do grupo-teste e as modificações do IG do grupo-controle.

\begin{tabular}{lcc} 
& $\mathrm{Z}$ & $\mathrm{P}$ \\
\hline Incisivos & $\mathbf{0 , 4 6 0}$ & $<0,646$ \\
Molares $^{*}$ & 2,874 & $<0,004$ \\
Áreas Interproxirnais* $^{*}$ & $\mathbf{3 , 2 6 0}$ & $<0,001$ \\
$\begin{array}{l}\text { Areas Vestibulares + } \\
\quad \text { Palatinas }\end{array}$ & 0,104 & $<0,920$ \\
\hline TOTAL & 1,879 & $<0,062$ \\
\hline
\end{tabular}

* diferençà significativa

TABELA 7 - Distribuição das freqüências (percentual) dos valores das unidades gengivais IG $=0,1$ e $2(+3$ ) no 1 ? e no 2 ? exames (após 9 me. ses de experiência).

\section{GRUPOS}

\begin{tabular}{ll} 
TESTE & \multicolumn{2}{c}{ CONTROLE } \\
19 EXAME 2 ? EXAME 19 EXAME 2 ? EXAME
\end{tabular}

VALORES

$\begin{array}{rrrrr}0 & 27,35 \% & 36,90 \% & 17,7 \% & 27,5 \% \\ .1 & 53,25 \% & 54,20 \% & 54,2 \% & 47,0 \% \\ 2 & 19,40 \% & 8,90 \% & 28,1 \% & 25,5 \%\end{array}$




\section{6 - DISCUSSÃo}

$\mathrm{Na}$ presente investigação verificouse o efeito de um programa de higiene oral (instruções iniciais sobre hi. giene oral e dieta e sessões de escovacão e uso de fio dental, supervisionados semanalmente) sobre as condições gengivais em escolares. TrabaIhou-se com dois grupos, um teste e um controle. $O$ grupo-teste participou do programa descrito acima, enquanto que o grupo-controle não de senvolveu qualquer atividade, além dos exames para o estabelecimento do IG.

Após 9 meses de experiência constatou-se uma diminuição no IG dos dois grupos.

A reduçao do IG do grupo-controle, a um nível de significância de 0,003 , foi inesperada. A melhora nas condições gengivais pode ser explica. da pelo fato das crianças sentirem que estavam recebendo atenção por participarem do levantamento do IG, e, a partir disso, modificarem seu comportamento em relação a higiene oral. Não pode ser descartada também a possibilidade de trocas de informações entre as crianças dos dois grupos, apesar de frequentarem turnos diferentes na escola. $O$ entusias. mo observado nas professoras e alu. nos para com a pesquisa pode ter sido transmitido para os integrantes do grupo-controle. Este resultado é sur. preendente, uma vez que diversos autores $13,49,50$, não encontraram meIhora nos indices gengivais e nos indices de higiene oral após a aplicação de programas motivacionais de higiene oral. Podshadley e Schwelkis (1970)50, num trabalho de instrução e motivação em higiene oral, conclui. ram que apenas uma instrução e uma demonstração dos procedimentos não é suficiente para ocasionar mudança de comportamento. Koch $(1970)^{22}$ num programa profilático intenso, semelhante ao desenvolvido na presente pesquisa, onde as crian. ças escovavam os dentes com dentifrícios com fluor, e usavam o fio dental semanalmente sob orientação, encontrou resultados, em relação ao estado da gengiva, diferentes dos deste trabalho. Verificou que, ao final da investigação (12 meses), não havia uma melhora significativa nas condições gengivais das crianças do grupoteste, embora esta houvesse sido perceptivel após o primeiro mês. Entretanto, Lindne e Koch21,26, após 3 anos de investigação, constataram uma melhora no IG em dois de seus grupos experimentais, que bochejavam quinzenalmente soluções de fluor $e$ água destilada, respectivamente, e que receberam uma única ins. trução de higiene oral. Estes autores também afirmam ter estranhado en. contrarem tais resultados.

No presente trabalho o grupo-controle diminuiu seu IG, aumentando, portanto, sua higiene oral, sendo que a única variável introduzida neste grupo foi o exame inicial.

No início da experiência o indice gengival médio do grupo-teste foi de 0,946 e $o$ do grupo-controle de 1,152 (tabela 2). Eles apresentavam uma diferença significativa, porque o balanceamento do grupo-teste com o grupo-controle foi realizado através do indice CPOS. Devido a não equivalência entre os indices gengivais dos dois grupos do experimento, não se comparou diretamente os resulta. dos encontrados do grupo-teste fren te alos do grupo-controle após 9 me. ses de experiência. Estes foram anali. sados de duas maneiras: (1) compara. 
ção da variação do indice gengival dentro de cada um dos grupos, isto é, testou-se a significância de diferença entre o 1 ? e o 2 ? exame do grupoteste e do grupo-controle respectivamente e, (2) comparação das diferencas entre os exames inicial e final do grupo-teste com as diferencas entre os mesmos exames do grupo-controle.

A variação do IG do grupo-teste entre $\circ 1$ e e o 2 ? exames foi de 0,216 , apresentando uma significância de $0,00003(Z=5,311)$. 0 grupo-controle teve uma variaç̃o entre os dois exames de 0,108 com uma significância de $0,003 \quad(Z=2,995)$ (Tabelas 3 e 6). Constata-se, portanto, que a melhora do grupo-teste foi bem mais significativa do que a do grupo-controle.

A melhora do IG dos dois grupos experimentais foi observada em todas as regiões examinadas (incisivos, molares, áreas interproximais e vestibulares + palatinas, tabela 3). Entretanto nota-se que foi bem significativa nas regiões dos molares e nas áreas interproximais. A redução percentual do IG das regiões dos molares foi de 31,6 para o grupo-teste e de 11,2 para o grupo-controle; e das áreas in. terproximais foi de 30,7 para o gru. po-teste e de 11,4 para o grupo-controle. Comparando-se as reduções do IG dos exames inicial e final do grupo-teste com as do grupo-controle, verificou-se que esta relação só é sig. nificativa nas regiões dos molares e áreas interproximais, exatamente onde, quando analisou-se separadamente os dois grupos, estavam localizadas as maiores diferenças (tabela 4). Convém salientar, entretanto, que as crianças melhoraram suas condições gengivais também nas demais regiões (incisivos e áreas vestibulares $+\mathrm{pa}$ latinas), mas esta melhora foi semeIhante nos dois grupos.

As prováveis explicações para o fato da diferença entre o IG dos dois grupos ter se concentrado nas regiões dos molares e nas áreas interproximais são:

(1) áreas interproximais - o uso do fio dental não é muito comum entre crianças do nosso meio; portanto como as crianças do grupo-teste foram ensinadas a usar o fio dental corretamente, e tiveram seu uso supervisionado, era provável que suas condições gengivais nestas áreas apresentassem melhora em relação às das criancas do grupo-controle, que provavelmente não haviam usado o fio dental, embora tivessem meIhorado sua higiene oral como um todo;

(2) Regiões dos molares - geralmente cuida-se melhor da higiene oral dos dentes anteriores. Como o grupo-controle aumentou sua higiene oral de maneira não orientada, na região posterior a melhora de sua higiene não foi tão perceptível como no grupo-teste. Durante as sessões de higiene oral supervisionadas frizava-se a necessidade das crianças limparem cuidadosamente as regiōes dos molares.

Analisando-se a melhora das condições gengivais nas regiōes dos molares e dos incisivos, verificou-se que esta é 2,3 vezes maior no grupo-teste e 1,3 vezes maior no grupo-controle. Estes achados são diferentes dos encontrados por Koch e Lindhe20,21, os quais verificaram que crianças que escovavam os dentes diariamente sob supervisão apresentavam uma dimi- 
nuição do IG da região anterior duas vezes maior do que nas regiões posteriores. Já Axelsson e Lindhe2 (1974), numa análise do IG de crianças após dois anos de profilaxia quinzenal, realizada por profissional, encontraram uma melhora mais significativa nas condições gengivais das regiões dos molares em relação com as dos incisivos, como no presente trabatho.

O programa de higiene oral oca. sionou uma melhora nas condições gengivais das crianças. Somente $8,90 \%$ das crianças do grupo-teste tiveram valores IG -2 após 9 meses de estudo, isto.é, apresentaram sinais de inflamacão moderada, gengivas avermelhadas ou sangrentas sob pressão. Aproximadamente $37 \%$ de todas as unidades gengivais examinadas possuiam IG - 0 , ou seja, ausência de inflamação (Tabela 7). As crianças do grupo-controle apresentaram um total de, aproximadamente, $26 \%$ de valores IG $=2$, isto é, $16,6 \%$ mais de unidades gengivais com inflamação moderada do que o grupo-teste.

\section{7 - CONCLUSÕES}

No desenvolvimento desta pesquisa conclui-se que:

- o estado da gengiva (baseado nas características clínicas dos diferen. tes graus de inflamação gengival) das regiões dos molares e das áreas interproximais, de escolares sub. metidos a um programa de higiene oral diferem estatisticamente do estado da gengiva dos escolares que não participaram do mesmo programa, a um nivel de 0,05. Em relação a gengiva das regiões dos incisivos e áreas vestibulares + palatinas esta diferença não foi significativa.
Além destas conclusões em relação às hipóteses, o estudo salientou os seguintes aspectos:

- houve uma melhora nas condições gengivais tanto do grupo-teste como do grupo-controle. Entretanto, a melhora do grupo-teste foi bem mais significativa;

- não se observou uma diferença estatisticamente significante entre os dois grupos nas condições gengiva is das regiões dos incisivos e das áreas vestibulares + palatinas, pois a me. Ihora nestas regiões foi semelhante nos grupos teste e controle;

- a melhora mais significativa nas condições gengivais das crianças do grupo-teste foi nas regiōes dos molares e áreas interproximais, coincidindo com as regiões onde normalmente a higiene oral é menor.

\section{SUMMARY}

An attempt was made to assess the effect of a prophylaxis programme on gingivitis in schoolchildren. A total of 182 children, aged 8 - 10 years and attending an elemen. tary school in Porto Alegre, participated. Ninety-one of the 182 children were used as an experimental group; the remaining 91 , as a control group. The state of the gingiva were determined in a baseline examination. The prophylaxis programme was given to the experimental group and consisted of the following measures: supervised brushing of the teeth (with the help of disclosing solution) and dental flossing once a week at school; supply of toothbrushes and dental floss for daily use at home; and instruction in oral hygiene and diet. 
The results after nine months of treatment showed that the test group had low IG (molars and proximal surfaces).

\section{REFERÊNCIAS BIBLIOGRÁFICAS}

1 - ALEXANDER, A.G. et alii - A study of the growth of plaque and the efficiency of self cleasing mechanism. Dent. Pract., 19:293-7, 1969.

2 - AXELSSON, P. \& LINDHE, J. - The effect of a preventive programme on dental plaque, gingivitis and caries in school-children. Results after one and two years. J. Clin. Periodontol., 1:126-38, 1974.

3 - AXELSSON, P. \& LINDHE, J. - Effect of fluorid on gingivitis and dental caries in a preventive program based on plaque control. Community Dent. Oral Epidemiol., 3:156-60, 1975.

4 - AXELSSON, P. \& LINDHE, J. - The effect of a plaque control program on gingivitis and dental caries in school children. J. Dent. Res., 56: 142-C, 1977. Special Issue C.

5 - AXELSSON, P. \& LINDHE, J. - Effect controlled oral hygiene procedures on caries and periodontal disease in adults. J. Clin. Periodontol,, 5:133-51, 1978.

6 - BACKER DIRKS, O. et alii - Principal requirements for controlled clinical trials. Int. Dent. J., 17.93-103, 1967.

7 - BERENIE, J. et alii - The relationship of frequency of toothbrushing in hygiene, gingival health and caries experience in schoolchildren. J.Public Health Dent., 33:160-71, 1973.

8 - BERGENHOLTZ, A. - Mechanical cleaning in oral higiene. In: FRANSEN, A. Oral Hygiene. A symposium held at Malmö, Sweden, 1971. Denmark, Munksgaard, 1972. p.27-60.

9 - CLARK, C.A. et alii - Eliminating dental plaque in the six th grade. J. Public Health Dent. 33:70-4, 1973.

10 - ENGLANDER, H.R. \& KEYES, P.H. - Control of Streptococcus mutans, plaque and dental caries in hamsters with topically applied vancomycin. Arch. Oral. Biol. 18:409-72, 1971.

11 - FITZGERALD, R.J. et alii - The effects of a dextranase preparation. on plaque and caries in hamsters, a preliminary report. Am. Dent. Assoc., 76:301-4, 1968.

12 - GIBBONS, R.J. \& VAN HOUTE, J. - Dental caries. Annual Review of Medicine, 26:121-36, 1975.

13 - GJERMO, P.E. - Effect of combined audio-visual motivation and individual instruction in oral hygiene. Apud: Scandinavian Symposium in Periodontology, 1967, abs. 19. J. Periodont. Res., 2.248, 1967.

14 - GREENE, J.C. - Periodontal disease in Indiana: Report of an epidemiological study. J. Dent. Res., 39:302-12, 1960.

15 - GUGGENHEIM, B. et alii - Caries and plaque inhibition by mutanase in rats. Caries Res., 6.289-97, 1972. 
16 - JACKSON, D. - Errors in clinical trials. Advances Fluorine Research, Oxford, 4.23-32, 1966. Apud. MOREIRA, B.H.W. Estudo sobre os efeitos de bochechos com solução molar de fluoreto de sódio, na prevenção da cárie dental. Piracicaba (Fac. de Odont. de Piracicaba da Univ. Est. de Campinas) 1970. 81f. (Tese).

17 - JENSEN, S.B. eţalii - Experimental gingivits in man. IV Vancomycin induced changes in bacterial plaque composition as related to development of gingival inflamation. J. Periodont. Res., 3.284-92, 1968.

18 - KEYES, P.H. - Research in dental caries. J. Am. Dent. Assoc., 76:1357. 73, 1968.

$19-\mathrm{KOCH}, \mathrm{G}$. \& LINDHE, J. - The effect of supervised oral hygiene on the gingiva of children. The effect of toothbrushing. Odontol. Revy. 16: 327-35, 1965.

$20-\mathrm{KOCH}, \mathrm{G}$. - Effect of sodium fluoride in dentifrice and mouthwash on incidence of dental caries in schoolchildren. Odontol. Revy., v.18, 1967. 125p. suppl. 12.

$21-\mathrm{KOCH}, \mathrm{G}$. \& LINDHE, J. - The state of the gingivas and the caries increment in schoolchildren during and after withdrawal of various prophy. latic measures. In: MCHUGH, W.E. (ed): Dental plaque. Edinburg \& London, E.S. Livingstone, 1970. p.271-81.

$22-\mathrm{KOCH}, \mathrm{G}$. - Selection and caries prophylaxis of children with high caries activity. Odontol. Revy, 21:71-81, 1970.

23 - KRASSE, B. - Group report: mechanical cleaning in oral hygiene. In: FRANSEN, A. Oral Hygiene, Munksgaard, 1972. p.60-2.

24 - LANG, N.P. et alii - Effect of toothbrushing frequencey on gingiva health. J. Dent. Res., 51:1314-5, abs. n? 33, 1972. Suppl.

25 - LARSON, R.H. et alii - Effect of denydroacetic acid and tetracycline on caries activity and its transmission in the rat. J. Dent. Res., 42.95-102, 1963.

26 - LINDHE, J. et alii - The effect uf supervised oral hygiene on the gingiva of children. Effect of mouthrinsing. J. Periodont. Res., 1.268-75, 1968.

27 - LINDHE, J. \& WICEN, P.O. - The effects on the gingivas of chewing fibrous foods. J. Periodont. Res. 4:193-201, 1969.

28 - LINDHE, J. et alii - Influence of topical application of chlorhexidine on chronic gingivitis and gingival wound healing in the dog. Scand. J. Dent. Res. 78.471-8, 1970.

29 - LINDHE, J. \& AXELSSON, P. - The effect of controlled oral hygiene and topical fluoride application on caries and gingivitis in swedish schoolchildren. Community Dent. Oral Epidemiol., 1.9-16, 1973.

30 - LINDHE, J. et alii - Experimental periodontitis in the beagle dog. Int. Dent. J. 23:432.7, 1973.

31 - LINDHE, J. et alii - Effect of proper oral hygiene on gingivitis and dental caries in swedish schoolchildren. Community Dent. Oral Epidemiol. 3:150-5, 1975.

32 - LISTGARTEN, M.A. - Dental plaque: it's structure and prevention. J. Dent. Child, 39:347-52, 1972. 
33 - LISTGARTEN, M.A. - Prevention of periodontal disease in the future. J. Clin. Periodontol., 6.61-6, 1979.

34 - LÖE, H. \& SILNESS, J. - Periodontal disease in pregnancy. I. Prevalence and severity. Acta Odontol. Scand. 21.533-51, 1963.

35 - LÖE, H. et alii - Experimental gingivitis in man. J. Periodont., 36:177. 87, 1965.

36 - Ln̈F, H. et alii - Experimental gingivitis in man. III. The influence of antibiotics on gingival plaque development. J. Periodont. Res., 2:282.9, 1967.

37 - LÖE, H. - A review of the prevention and control of plaque. In: MCHUGH, W.D. (ed): Dental Plaque. Edinburg \& London, E.S. Li. vingstone, 1970. p.259-70.

38 - LÖE, H. - Present status and direction for future research on the etiology and prevention for periodontal disease. J. Periodont. Res. 4:38-9, 1969. Suppl.

39 - LÖE, H. \& SCHIOTT, C.R. - The effect of mouthrinses and topical appli. cation of chlorhexidine on the development of dental plaque and gingivitis in man. J. Periodont. Res. 5:79-83, 1970.

40 - LÖE, $H$. et alii - Innibition of experimental caries by plaque prevention. The effect of chlorhexidine mouthrinses. Scand. J. Dent. Res., 80:1-9, 1972.

41 - LÖE, H. - Plaque control in periodontal disease. J. Am. Dent. Assoc. 87 : 1034-6, 1973.

42 - LÖE, H. - Mecanical and chemical control of dental plaque. J. Clin. Periodontol., 6:32-6, 1979.

43 - LÖVDAL, A. et alii - Incidence of clinical manifestation of periodontal disease in light of oral hygiene and calculus formation. J. Am. Dent. Assoc., 56.21-33, 1958.

44 - MANDEL; I.D. - New approaches to plaque prevention. The Dental Clinic of North America, 16.661-71, 1972.

45 - MARTHALER, T.M. Estimation of sample size for longitudinal clinical caries trials. Helv. Odont. Acta., 11:168-74, 1967.

46 - MCMILLAN, R.S. \& WOLFF, A.E. - Periodontal disease. In: PELTON; W.J.; DUNBAR, J.B.; MCMILLAN, R.S. The epidemiology of oral health. Cambridge, Harvard University, 1969. p.15-41.

47 - MIKKELSEN, L. et alii - The effect of dextranase on plaque formation in humans. 1970. Apud. A review of the prevention and control of plaque. In: MCHUGH, W.D. (ed): Dental Plaque. Edinburg \& London, E.S. Livingstone, 1970. p.259-70.

48 - MITCHELL, D.F. \& HOLMES, L.A. - Topical antibiotic control of dentogingival plaque. J. Periodontol., 38:202-8, 1965.

49 - PODSHADLEY, A.G. - Oral hygiene performance of elementary schoolchildren following dental health education. J. Dent. Child., 37:298$302,1970$. 
50 - PODSHADLEY, A.G. \& SCHWETKLE, S. - The effectiveness of two educational programs in changing the performance of oral hygiene by elementary schoolchildren. J. Public. Health Dent., 30:17-20, 1970.

51 - PYKE, S.R. - Prevention in dentistry as viewed by a dental educator. J. Public Hea/th Dent., 33:75-81, 1973.

52 - SIEGEL, S. - Non-parametric statistics, for the behavioral sciences. New York, Mc Graw-Hill Book Company, 1956.

53 - STALLARD, R.E. et alii - The effect of an antimicrobial mouthrinse on dental plaque calculus and gingivitis. J. Periodont. Res., 4:37-8, (abs. n? 32) 1969. Suppl.

54 - SUOMI, J.D. et alii - The effect of controlled oral hygiene procedures on the progression of periodontal disease in adults: Results after two years. J. Periodontol., 40:416-20, 1969.

55 - SUOMI, J.D. et alii - The effect of controlled oral hygiene procedures on the progression of periodontal disease in adults: Results after third and final years. J. Periodont., 42:152-60, 1971.

56 - SUOMI, J. D. - Prevention and control of periodontal diseases. J. Am. Dent. Assoc., 83:1271-87, 1975.

57 - TERHUNE, J.A. - Predicting the readiness of elementary schoolchildren to learn and effective dental flossing tecnich. J. Am. Dent. Assoc., 86: 1332-6, 1973.

58 - THEILADE, E. et alii - Experimental gingivitis in man. II. A longitudinal clinical and bacteriological investigation. J. Periodont. Res., 1:1-13, 1966.

59 - WAERHAUG, J. - Epidemiology of periodontal disease - review of literature. In: WORLD WORKSHOP IN PERIODONTICS. An Arbor, The American Academy of Periodontology and The University of Michigan, 1966. p.179-211.

60 - WAERHAUG, J. - Prevalence of periodontal disease in Ceylon - Association with age, sex, oral hygiene, malnutrition, betel and tabocco consumption and ethnic group, final report. Acta Odontol. Scand. 25: 205-31, 1967. 